\title{
Fatal overdoses involving hydromorphone and morphine among inpatients: a case series
}

\author{
Amanda Lowe BScFS (Hons) MSc, Michael Hamilton MD MPH, Julie Greenall BScPhm MHSc, \\ Jessica Ma BScPhm, Irfan Dhalla MD MSc, Nav Persaud MD MSc
}

Abstract

Background: Opioids have narrow therapeutic windows, and errors in ordering or administration can be fatal. The purpose of this study was to describe deaths involving hydromorphone and morphine, which have similar-sounding names, but different potencies.

Methods: In this case series, we describe deaths of patients admitted to hospital or residents of long-term care facilities that involved hydromorphone and morphine. We searched for deaths referred to the Patient Safety Review Committee of the Office of the Chief Coroner for Ontario between 2007 and 2012, and subsequently reviewed by 2014. We reviewed each case to identify intervention points where errors could have been prevented.

Results: We identified 8 cases involving decedents aged 19 to 91 years. The cases involved errors in prescribing, order processing and transcription, dispensing, administration and monitoring. For 7 of the 8 cases, there were multiple (2 or more) possible intervention points. Six cases may have been prevented by additional patient monitoring, and 5 cases involved dispensing errors.

Interpretation: Opioid toxicity deaths in patients living in institutions can be prevented at multiple points in the prescribing and dispensing processes. Interventions aimed at preventing errors in hydromorphone and morphine prescribing, administration and patient monitoring should be implemented and rigorously evaluated.

$\mathrm{P}$ atients are unintentionally harmed in up to $25 \%$ of hospital admissions, and medication incidents account for a large proportion of these adverse events. ${ }^{1,2}$ Opioids, which are commonly used in hospitals to alleviate pain, have a relatively narrow therapeutic window that can vary based on patient comorbidities, tolerance and the use of other medications (e.g., benzodiazepines). Patients often receive multiple opioid formulations during the same admission because different routes of administration and different agents are employed depending on the patient's clinical situation and the prescriber's preference. The switch from one agent to another is a potential source of medication error; these errors may be especially common with opioids because of differing half-lives, incomplete cross-tolerance, similar names, dose conversion errors and the large number of available products..$^{3-5}$ Opioids are commonly prescribed in Canada and are the medication class most frequently identified in harmful medication incidents voluntarily reported to the Institute for Safe Medication Practices Canada. ${ }^{5}$

Hydromorphone and morphine are the most frequently implicated opioids in harmful medication incidents. ${ }^{6}$ Hydro- morphone is about $5-7$ times more potent than morphine. As a result, patients may be harmed if health care professionals who order, dispense and administer these drugs do not recognize this crucial difference between these medications, which have similar names. ${ }^{7}$ We report a series of accidental fatal overdoses of hydromorphone or morphine among hospital inpatients and long-term care residents reviewed by the Office of the Chief Coroner for Ontario between 2007 and 2012. We also consider factors that led to these adverse events and make recommendations to reduce the potential for similar incidents in the future.

Competing interests: None declared.

Disclaimer: Nav Persaud is an Associate Editor for CMAJ Open and was not involved in the editorial decision-making process for this article.

This article has been peer reviewed.

Correspondence to: Nav Persaud, nav.persaud@utoronto.ca CMAJ Open 2017. DOI:10.9778/cmajo.20160013 


\section{Methods}

\section{Setting}

In Ontario (population 13.6 million), the Coroners Act states that all deaths that are sudden and unexpected, or from any cause other than disease, must be reported to a coroner.

\section{Study population}

The Office of the Chief Coroner for Ontario established a Patient Safety Review Committee in 2005 to review coroners' cases where the investigating coroner believes the death may have been associated with a preventable adverse event to make recommendations to prevent future similar events. We (A.L. and N.P.) identified all cases examined by the Patient Safety Review Committee between 2007 and 2012 that involved hydromorphone or morphine in patients admitted to hospital or residents of long-term care facilities.

\section{Design}

For each identified death, we (A.L. and N.P.) reviewed the Patient Safety Review Committee case review file, the reports of the investigating coroner, autopsy reports, relevant portions of the hospital medical record and toxicology reports, where available and applicable. We recorded demographic (age and sex) and medical information (medical history, medications ordered, medication administered and events leading to death) and then drafted a narrative summary for each case.

After reviewing all cases, we (A.L., M.H., J.G., J.M., I.D. and N.P.) identified the points at which each death could have been prevented using the stages of prescribing employed elsewhere. ${ }^{8}$ The purpose of this framework was to identify the stage of the process where adverse drug events occurred and to help determine which adverse drug events are preventable. ${ }^{8}$ The original framework included 4 stages: ordering, transcribing, dispensing and administration. ${ }^{8}$ We renamed 2 stages: we use "prescribing" instead of "ordering" (because prescribing is a more general term that includes decisions about whether or not to order medications) and "processing" instead of "transcribing" (because the former applies to both computer and paper orders). We also added the "monitoring" stage because it is particularly important in opioid prescribing. Two reviewers (N.P. and A.L.) independently reviewed each case for potential intervention points and resolved disagreements by discussion. The determinations were then reviewed by the other investigators.

\section{Ethics approval}

This study was approved by the research ethics board of St. Michael's Hospital, Toronto.

\section{Results}

We identified 8 accidental fatal opioid overdoses involving hydromorphone and morphine between 2007 and 2012 that involved different factors (Table 1). The potential intervention points are summarized in Table 2 .

\section{Case 1}

An 81-year-old woman was admitted to hospital for emergent surgical treatment of a colonic perforation. Two weeks after the operation, the patient's condition deteriorated and symptomatic (or "comfort") care was instituted, including an order for hydromorphone (1 $\mathrm{mg}$ subcutaneously every $4 \mathrm{~h}$ as needed). After detection of a discrepancy in an end-of-shift narcotic count, it was determined that a nurse had erroneously drawn $0.5 \mathrm{~mL}$ from a $50 \mathrm{mg} / \mathrm{mL}$ vial of morphine instead of a $2 \mathrm{mg} /$ $\mathrm{mL}$ vial of hydromorphone. The patient had received $25 \mathrm{mg}$ of morphine instead of the intended $1 \mathrm{mg}$ of hydromorphone (an error of about fivefold after accounting for the difference in potency between the 2 drugs).

\section{Case 2}

A healthy opioid-naive 22-year-old man was admitted to hospital with acute upper back pain. Morphine was initially ordered at $1-5 \mathrm{mg}$ intravenously every 2 hours as needed, and was later increased to 5-10 $\mathrm{mg}$ intravenously every 2 hours as needed. Owing to poor pain control, an order was written in the evening to discontinue morphine and start hydromorphone at 5-10 mg intravenously every 4 hours as needed. The next morning, the patient was found without vital signs. Resuscitation efforts were unsuccessful.

\section{Case 3}

An 82-year-old wheelchair-bound man with peripheral vascular disease and chronic obstructive pulmonary disease was admitted to a palliative care ward after a fall. Hydromorphone (0.2-0.4 mg subcutaneously) was ordered as pain control for the patient. A nurse documented hydromorphone $0.4 \mathrm{mg}$ as given subcutaneously. The patient died about 30 minutes after receiving the injection. A coroner's investigation determined that the dose of hydromorphone had been drawn from a vial of hydromorphone with a concentration of $10 \mathrm{mg} / \mathrm{mL}$, and that this contributed to a 10 -fold overdose whereby the patient received $4 \mathrm{mg}$ hydromorphone instead of the intended $0.4 \mathrm{mg}$.

\section{Case 4}

An 86-year-old medically complex male resident of a nursing home was being cared for with palliative intent. A hydromorphone infusion was ordered via computerized prescriber order entry as $5 \mathrm{mg}$ in $50 \mathrm{~mL}$ (i.e., $0.1 \mathrm{mg} / \mathrm{mL}$ ) to run at 0.2 $\mathrm{mg} / \mathrm{h}$. An additional note in a comment field separate from the order entry area indicated the concentration was to be 1 $\mathrm{mg} / \mathrm{mL}$. The computer calculated the rate of administration as $2 \mathrm{~mL} / \mathrm{h}$ based on the information entered in the order fields, and this information was part of the printed order. The order was entered after pharmacy hours when no pharmacist was available for verification. The nurse prepared the infusion as $50 \mathrm{mg} / 50 \mathrm{~mL}(1 \mathrm{mg} / \mathrm{mL})$ as specified in the comment field and set the pump to run at $2 \mathrm{~mL} / \mathrm{h}$ as per the rate field in the printed order. An independent double check was conducted by a second nurse before starting the infusion. About 90 minutes after starting the infusion, a nurse noted the discrepancy between the dosage and the concentration. The infusion was stopped and the physician and family were 


\begin{tabular}{|c|c|c|c|c|c|c|}
\hline Case & $\begin{array}{l}\text { Patient } \\
\text { age, yr }\end{array}$ & Sex & Setting & Ordered or intended & Action precipitating death & Incident \\
\hline 1 & 81 & Female & Hospital & $\begin{array}{l}\text { Ordered: hydromorphone } \\
1 \mathrm{mg}(0.5 \mathrm{~mL} \text { from } 2 \mathrm{mg} / \\
\mathrm{mL} \text { vial) subcutaneously }\end{array}$ & $\begin{array}{l}\text { Administered: morphine } \\
25 \mathrm{mg}(0.5 \mathrm{~mL} \text { from } 50 \\
\mathrm{mg} / \mathrm{mL} \text { vial }) \\
\text { subcutaneously }\end{array}$ & $\begin{array}{l}\text { About 5-fold excessive } \\
\text { dose }\end{array}$ \\
\hline 3 & 82 & Male & $\begin{array}{l}\text { Palliative } \\
\text { care }\end{array}$ & $\begin{array}{l}\text { Ordered: } \\
\text { hydromorphone increased } \\
\text { from } 0.2 \text { to } 0.4 \mathrm{mg} \\
\text { subcutaneously as } \\
\text { necessary for pain } \\
\text { management }\end{array}$ & $\begin{array}{l}\text { Administered: } \\
\text { hydromorphone } 4 \mathrm{mg} \\
\text { (dose drawn from a } 10 \\
\mathrm{mg} / \mathrm{mL} \text { concentration vial } \\
\text { to give an actual dose of } \\
4 \mathrm{mg} \text { ) }\end{array}$ & $\begin{array}{l}\text { About } 10 \text {-fold excessive } \\
\text { dose }\end{array}$ \\
\hline 4 & 86 & Male & $\begin{array}{l}\text { Nursing } \\
\text { home }\end{array}$ & $\begin{array}{l}\text { Ordered: } \\
\text { hydromorphone } 0.2 \mathrm{mg} / \mathrm{h} \\
\text { intravenously. }\end{array}$ & $\begin{array}{l}\text { Administered: } \\
\text { hydromorphone } 2 \mathrm{mg} / \mathrm{h} \\
\text { intravenously }\end{array}$ & $\begin{array}{l}\text { About } 10 \text {-fold excessive } \\
\text { dose }\end{array}$ \\
\hline 5 & 90 & Female & Hospital & $\begin{array}{l}\text { Initial order: } \\
\text { long-acting morphine } \\
15 \text { mg twice daily } \\
\text { Second order: } \\
\text { discontinuation of } \\
\text { morphine; hydromorphone } \\
2 \text { mg orally every } 4 \text { h as } \\
\text { needed }\end{array}$ & $\begin{array}{l}\text { Administered: } \\
\text { both morphine and } \\
\text { hydromorphone } \\
\text { administered }\end{array}$ & $\begin{array}{l}\text { About 2.5-fold excessive } \\
\text { dose }\end{array}$ \\
\hline
\end{tabular}

Table 2: Potential intervention points for error prevention or harm mitigation

\begin{tabular}{|c|c|c|c|c|c|}
\hline Case & Prescribing & Order processing & Dispensing & Administration & Patient monitoring \\
\hline 1 & & & $\bullet$ & & $\bullet$ \\
\hline 2 & $\bullet$ & & & & $\bullet$ \\
\hline 3 & & & $\bullet$ & & \\
\hline 4 & $\bullet$ & - & & - & \\
\hline 5 & $\bullet$ & - & & & $\bullet$ \\
\hline 6 & & & $\bullet$ & $\bullet$ & $\bullet$ \\
\hline 7 & $\bullet$ & & $\bullet$ & $\bullet$ & - \\
\hline 8 & & & $\bullet$ & $\bullet$ & $\bullet$ \\
\hline
\end{tabular}


contacted. A decision was made not to reverse the effect of the opioid and the patient died about 8 hours later. Aspiration pneumonia due to stroke was deemed to have caused death in the context of an opioid administration error.

\section{Case 5}

A 90-year-old woman presented to the emergency department after a fall. She was admitted to the hospital for pain management. Long-acting morphine was ordered $(15 \mathrm{mg}$ orally, twice daily). Two days after admission, an order was written to discontinue morphine and start hydromorphone at $2 \mathrm{mg}$ orally every 6 hours (standing dose) and $2 \mathrm{mg}$ orally every 4 hours as needed. The discontinuation order for morphine was not transcribed and the patient was administered both the morphine and hydromorphone for 3 days. She was found unresponsive, with a low respiratory rate. The orders were then reviewed, and the error was detected. The opioids were held and opioid toxicity was treated with 1 dose of naloxone $(0.2 \mathrm{mg}$ intravenously). The patient's vital signs normalized after the administration of naloxone. An hour later, the patient was found unresponsive with a low respiratory rate. because there was a "do not resuscitate" (DNR) order in place, no resuscitation was started. Opioid toxicity was deemed to have caused death.

\section{Case 6}

A 42-year-old woman with a 12-year history of breast cancer was admitted to hospital for rehydration owing to an esophageal stricture. Investigations during admission showed metastases to bone and possibly brain. Her resuscitation status was changed to DNR. Morphine was ordered for pain management. An order for morphine, 2-3 mg intravenously every 4 hours as needed, with a note to hold if the respiratory rate was less than 10, was instituted. Overnight, $2 \mathrm{mg}$ morphine was given intravenously with good effect. The following afternoon, $3 \mathrm{mg}$ hydromorphone was inadvertently given intravenously instead of the intended morphine. The error was detected by a nurse 80 minutes later. The patient was assessed and was noted to be sleeping with stable vital signs. Fifteen minutes later, the patient was noted to be apneic by a family member. No resuscitation measures were implemented owing to her DNR status.

\section{Case 7}

A 19-year-old woman was admitted with an acute painful exacerbation of her sickle cell disease. Her pain proved difficult to control. On her admission day, she received $6.5 \mathrm{mg}$ of hydromorphone and $12 \mathrm{mg}$ of morphine via both subcutaneous and intravenous routes. On day 2 of her admission, she received a total of $22 \mathrm{mg}$ of hydromorphone intravenously. On day 3 of her admission, she received about $22.5 \mathrm{mg}$ of hydromorphone intravenously and $120 \mathrm{mg}$ of codeine by mouth. She slept most of the day and was noted to be drowsy in the evening. An antinauseant was not given owing to her drowsiness and, despite a reported pain level of 10/10, she declined her routine hydromorphone dose at midnight. At 01:00 she was given a dose of dimenhydrinate. At 02:00 she indicated her nausea was better and received the scheduled dose of $4 \mathrm{mg}$ of hydromorphone intravenously. She was found with no vital signs about 4 hours later. Hydromorphone overdose as the cause of death was supported by toxicology results showing a blood hydromorphone concentration high enough to cause death.

\section{Case 8}

A 91-year-old female resident of a long-term care home was admitted to hospital twice in the days leading to her death for the treatment of pneumonia and influenza. Her medical history included hypertension, chronic obstructive pulmonary disease, hyperthyroidism, asthma, atrial fibrillation, peptic ulcer disease with upper gastrointestinal bleeds and congestive heart failure. Comfort care was instituted on the second day of admission. A standing order for $4 \mathrm{mg}$ subcutaneous morphine every 4 hours was written, with $2 \mathrm{mg}$ morphine per hour subcutaneously as needed for pain. Two doses of $2 \mathrm{mg}$ morphine were given, and notes document that as a result of this the scheduled standing $4 \mathrm{mg}$ morphine doses were not given. An assessment of the patient showed her blood pressure and oxygen saturation were low, and she was lethargic. The next day she was given $4 \mathrm{mg}$ morphine. Three hours later, she was found without vital signs, and no resuscitation was attempted as per advance directives. Through the routine medication count process, it was determined that she had received $4 \mathrm{mg}$ hydromorphone, as opposed to the prescribed $4 \mathrm{mg}$ morphine.

\section{Interpretation}

The 8 deaths involving hydromorphone and morphine we describe here might have been prevented at multiple stages of the medication use process: prescribing, order processing and transcription, dispensing, administration and monitoring.

This case series provides detailed descriptions of the circumstances leading to unintentional (or accidental) opioid overdoses and complements several population-based studies that show the substantial incidence of opioid overdose, many of which are related to medication misuse. , $, 9,10$ Adverse drug events are often related to ordering or administration, and serious adverse drug events are often $(42 \%)$ preventable. ${ }^{8}$ The cases presented here show that fatal opioid overdoses occur even when opioids are used in medically supervised settings and show the need for a comprehensive approach to reducing harms from opioids among patients admitted to hospital. The development of such an approach could inform the development of a parallel approach for outpatients with opioid prescriptions.

The prescribing stage of the medication use process is the first point at which errors can occur (cases 2, 4, 5 and 7). This includes the decision to prescribe medication or not, which medication to prescribe, the dose, the dosage form, the route of administration, frequency and other instructions. These complexities are exacerbated by the finding that many clinicians misunderstand the pharmacologic characteristics of different opioids. A 2012 survey of more than 3000 health care workers from all disciplines showed knowledge deficits in 
many areas of opioid use, particularly with respect to pharmacologic properties (e.g., onset, peak effect, duration) and dosage calculations. ${ }^{11}$ Furthermore, the survey showed that many practitioners were unaware of the need to modify dosages of opioids for patients using potentiating drugs or patients with chronic conditions such as respiratory disease. To attempt to mitigate these errors, restrictions on opioid prescribing, such as an automatic warning that the suggested hydromorphone dose is $0.2-0.5 \mathrm{mg}$ intravenously and a limit of $1 \mathrm{mg}$ per dose of hydromorphone for initial treatment have been implemented in some facilities. ${ }^{12}$ Other organizations have instituted early pharmacist review of opioid orders to detect elevated dosages of opioids. ${ }^{13,14}$

The variety of opioid products available on wards contributes to order processing and medication administration errors (cases 1, 3, 4, 5, 6 and 7). Case 3 involved a 10-fold overdose of hydromorphone. A contributor to this error is the disparity between common initial doses of hydromorphone and commercially marketed products. Initial doses of intravenous hydromorphone for opioid-naive patients are often less than $1 \mathrm{mg}$. However, the smallest parenteral dosage form commercially available in Canada is $2 \mathrm{mg} / \mathrm{mL}$. This problem is compounded when high-concentration or high-dose opioid products are available in patient care areas, as in cases 1 and 3 . The removal of high-concentration or high-dose hydromorphone (> $2 \mathrm{mg} / \mathrm{mL}$ ) and morphine (> $15 \mathrm{mg} / \mathrm{mL}$ ) from general patient care areas has been implemented as a safety strategy to reduce the potential for overdose, and this procedure has been adopted by some accreditation bodies to enhance patient safety. ${ }^{15}$ Provision of standard volume charts for $2 \mathrm{mg} / \mathrm{mL}$ hydromorphone to assist nurses in preparing small doses has also been recommended. ${ }^{6}$

Look-alike, sound-alike problems have occurred between hydromorphone and morphine. ${ }^{7,16}$ Although initial recommendations suggested a change in the generic name of hydromorphone to reduce the risk of fatal hydromorphone-morphine substitution errors, ${ }^{17}$ the US Food and Drug Administration opted to replace standard fonts with "TALLman" lettering (i.e., "HYDROmorphone"). ${ }^{18}$ This has also been adopted by some manufacturers of generic hydromorphone in Canada; however, the effectiveness of this strategy is unknown, and these label changes do not necessarily reduce the risk of prescribing errors. Additional recommended but unproven strategies to decrease the potential for substitution errors include segregating hydromorphone and morphine in storage areas and implementing independent double checks, including bar coding, before medication administration. ${ }^{7}$ Restriction of hospital formularies to include a limited number of opioids and dosage forms is an additional strategy that could be considered to address confusion between opioids. ${ }^{7}$

Monitoring is a crucial stage of the medication use process, because it represents the last opportunity to detect harm (cases 1, 2, 5, 6 and 7). This detection of harm, however, requires knowledge of the potential effects of the medication, as well as a systematic approach to assessment of the patient. This is particularly important because opioid toxicity can almost always be reversed with naloxone in a care setting if detected promptly. ${ }^{19}$ The ability to intervene effectively is dependent upon recognition of the signs and symptoms of overdose, as well as the proper and knowledgeable use of naloxone relative to the opioid dosage form administered. This is illustrated in case 5 , in which a single dose of naloxone was given to a patient who had received a long-acting opioid.

System-based approaches, such as electronic prescribing systems with decision support for evidence-based prescribing and monitoring, use of predefined order sets that include monitoring and intervention parameters, including the management of suspected overdose, and enhanced use of technology such as "smart" infusion pumps with embedded drug libraries and bar code verification at the bedside may prevent fatalities. The availability of dosage forms that are aligned with usual doses ordered would decrease the likelihood of preparation errors associated with complex calculations and manipulations at the bedside. Future work should rigorously evaluate the effectiveness of preventive measures.

\section{Limitations}

Our methods do not allow us to estimate the incidence of fatal opioid overdoses in Ontario hospitals or the risk per administration. Because the coroner's office only investigates deaths that are reported, and because many deaths are not investigated, it is likely that there were more than 8 fatal opioid overdoses involving hydromorphone and morphine among inpatients in Ontario during the study period.

The case descriptions and analyses relied heavily on the accuracy of medical documentation. In some cases, documentation was likely insufficient to determine all the contributing factors. Although our study focuses on hydromorphone and morphine, other opioids such as oxycodone, fentanyl and methadone have also been implicated in errors that caused deaths in health care facilities. ${ }^{20,21}$ No inferences about the relative safety of these medications compared with others can be drawn from this case series.

\section{Conclusion}

These cases illustrate the opportunities to prevent deaths involving hydromorphone and morphine among inpatients and the need to consider potential intervention points at each stage of the medication use process. In addition, these cases highlight the importance of reporting and analyzing suspected medication errors to detect vulnerabilities in practices, design preventive strategies and inform future research, including studies of interventions to prevent fatalities.

\section{References}

1. Landrigan CPPG, Bones CB, Hackbarth AD, et al. Temporal trends in rates of patient harms resulting from medical care. N Engl 7 Med 2010;363: 2124-34.

2. Baker GRNP, Flintoft V, Blais R, et al. The Canadian adverse events study: the incidence of adverse events among hospital patients in Canada. CMAF 2004; 170:1678-86.

3. Ostini R, Kirkpatrick CM, Monteith GR, et al. Quality use of medicines medication safety issues in naming; look-alike, sound-alike medicine names. Int 7 Pharm Pract 2012;20:349-57.

4. Madadi P, Lauwers AE, Koren G. Characteristics of opioid-users whose death was related to opioid-toxicity: a population-based study in Ontario, Canada. PLoS One 2013;8:e60600. 
5. ISMP Canada Safety Bulletin : Top 10 drugs reported as causing harm through medication error. Toronto: Institute for Safe Medication Practices Canada; 2006

6. ISMP Canada Safety Bulletin: Safeguards for HYDROmorphone - results of a targeted demonstration project. Toronto: Institute for Safe Medication Practices Canada; 2013.

7. ISMP Canada Safety Bulletin: An omnipresent risk of morphine hydromorphone mix-ups. Toronto: Institute for Safe Medication Practices Canada; 2004.

8. Bates DW, Cullen DJ, Laird N, et al. Incidence of adverse drug events and potential adverse drug events. Implications for prevention. ADE Prevention Study Group. 7AMA 1995;274:29-34.

9. Paulozzi LJBD, Xi Y. Increasing deaths from opioid analgesics in the United States. Pharmacoepidemiol Drug Saf 2006;15:618-27.

10. Wallage HRPJ. Hydromorphone-related fatalities in Ontario. 7 Anal Toxicol 2006;30:202-9.

11. ISMP Canada Safety Bulletin: Identifying knowledge deficits related to HYDROmorphone. Toronto: Institute for Safe Medication Practices Canada; 2012.

12. Marcus H. Dilaudid-related morbidity and mortality from respiratory depression. The Doctor's Advocate, third quarter 2009.

13. Hospital pharmacy: Pharmacist First Dose Review [section 61-07-01-14]. In: North Dakota Administrative Code. Bismarck (ND): North Dakota Legislative Branch; [effective] 2012.

14. Pederson CA, Scheckelhoff DJ. ASHP national survey of pharmacy practice in hospital setting: prescribing and transcribing - 2010. Am 7 Health Syst Pharm 2011;68:669-88.

15. Required organizational practices handbook. Ottawa: Accreditation Canada; 2013.

16. Inadvertent mix-up of morphine and hydromorphone: a potent error. PA PSRS Patient Saf Advis 2007;4:86-8.

17. Event analysis report: hydromorphone/morphine event hospital. Toronto: Institute for Safe Medication Practices Canada; 2004.

18. Name Differentiation Project. Silver Spring (MD) United States Food and Drug Administration; (updated 2016). Available: www.fda.gov/drugs/drugsafety/ medicationerrors/ucm164587.htm (accessed 2017 Feb. 8)
19. Konieczko KMJJ, Barrowcliffe MP, Jordan C, et al. Antagonism of morphineinduced respiratory depression with nalmefene. Br 7 Anaesth 1988;61:318-23.

20. ISMP Canada Safety Bulletin: Deaths associated with medication incidents: learning from collaborative work with provincial offices of the Chief Coroner or Chief Medical Examiner. Toronto: Institute for Safe Medication Practices Canada; 2013.

21. Dy SMSA, Hicks RW, Morlock LL. Medication errors with opioids: results from a national reporting system. 7 Opioid Manag 2007;3:189-94.

Affiliations: Office of the Chief Coroner for Ontario (Lowe), Toronto, Ont.; Institute for Safe Medication Practices Canada (Hamilton, Greenall, Ma); St. Michael's Hospital, Health Quality Ontario and Department of Medicine and Institute for Health Policy, Management and Evaluation, University of Toronto (Dhalla); Department of Family and Community Medicine, St. Michael's Hospital, and Department of Family and Community Medicine, University of Toronto (Persaud), Toronto, Ont.

Contributors: Nav Persaud and Amanda Lowe conceived the study. Michael Hamilton, Julie Greenall, Jessica Ma and Irfan Dhalla assisted in analyzing and interpreting the data. Nav Persaud and Amanda Lowe drafted the manuscript. Michael Hamilton, Julie Greenall, Jessica Ma and Irfan Dhalla revised the manuscript for important intellectual content. All authors approved the final version and agreed to act as guarantors of the work.

Funding: Nav Persaud is supported by a PSI Graham Farquharson Knowledge Translation Fellowship.

Supplemental information: For reviewer comments and the original submission of this manuscript, please see www.cmajopen.ca/content/5/1/ E184/suppl/DC1 